\title{
DISCURSOS E IMAGENS DO TURISMO CULTURAL
}

\author{
Zara Pinto-Coelho \& Roque Pinto
}

\section{DISCOURSES AND IMAGES OF CULTURAL TOURISM}

\section{Âмвiто E овJETIVOS}

O turismo cultural (Richards, 2007; Smith, 2003) é reconhecido como uma área em crescimento da indústria cultural global. As iniciativas e estratégias conduzidas um pouco por todo o mundo para desenvolver este tipo de turismo, e para o tornar mais acessível, inclusivo, criativo e sustentável, são inúmeras e muito diversificadas (WNT, 2018). As realidades da indústria e da política portuguesa em matéria de turismo não constituem exceção, como deixa claro o plano definido para o turismo em Portugal, Visão Estratégia Turismo 2027, onde se define como eixo estratégico de ação futura a "valorização do território e das comunidades" (ET27, 2016, p. 51).

$\mathrm{Na}$ alçada das dinâmicas e mudanças que têm atravessado a chamada economia da cultura ou economia cultural (Yúdice, 2007), o discurso oficial do turismo cultural tem vindo a expandir os seus objetos, estando hoje evidentemente marcado por um entendimento da cultura (Cunha, 2015) que lhe empresta tonalidades antropológicas as "culturas vividas", a "cultura do quotidiano" figuram ao lado dos clássicos recursos como o património, museus e artes ditas eruditas (UNWT, 2018, p. 11) - coadunadas com a lógica do marketing experiencial.

Também na academia o interesse dos investigadores das ciências sociais pelo turismo cultural, nas suas diversas formas, tem vindo a crescer e a ganhar novas dinâmicas (Richards, 2018; Smith \& Richards, 2013; Smith \& Robinson, 2005), expressivas tanto da porosidade epistemológica do conhecimento produzido no campo, como da instabilidade, fluidez e contradições que marcam as sociedades contemporâneas.

Note-se que em Portugal o interesse que o tema suscita nos Estudos Culturais e na Comunicação tem sido diminuto e é relativamente recente (Brambília \& Baptista, 2016; Cadavez, 2017; Noval \& Serra, 2018; Sampaio, 2017), sendo neste aspeto claramente diferenciado do investimento no assunto em áreas como a Antropologia (Pereiro, 2009; Pereiro \& Fernandes, 2018; Silva, 2010), a Sociologia (Andrade, 2017; Fortuna, 2008; Joaquim, 2015; Marújo, 2014) ou a Geografia (Fernandes, 2016), fruto porventura das particularidades da emergência e expansão do campo a nível nacional (Martins, 2015; Sampaio, 2013).

Com a organização deste número da Revista Lusófona de Estudos Culturais, dedicado ao turismo que se define como cultural, pretendemos sublinhar a importância de investir na investigação do tema em contextos lusófonos - e em outros contextos marginalizados 
pela tradicional hegemonia da literatura anglo-saxónica (Dann \& Parrinello, 2009). Tal investigação deverá estar ancorada em preceitos de abertura e fluidez, quer dizer, situada no mundo e vinculada sempre a questionamentos críticos da relação entre cultura e poder (Martins, 2015).

A inter-relação analítica que colocamos no centro da discussão - entre discursos e imagens e a modelação/regulação da experiência turística - tem já acumulado um vasto trabalho teórico e crítico nos contextos dos debates sociológicos e antropológicos, e tem sido também explorado em áreas como a sociolinguística e análise do discurso (Francesani, 2014; Heller et al., 2014; Jaworski \& Pritchard, 2005; Moore, 2002), cultura visual (Burns, Palmer \& Lester, 2010) e literatura (Culler, 1989). O mesmo não se passa quando pensamos a questão do turismo promovido como cultural, de um ponto de vista crítico, no quadro das mobilidades (Araújo, Congo \& Pinto, 2015; Franklin \& Crang, 2011; Urry, 2007) e da progressiva tecnologização no mundo contemporâneo dos processos de estetização da experiência (La Rocca, 2017; Martins, 2002, 2007).

Esta coleção reúne contributos onde se discutem questões que têm marcado a agenda crítica cultural da investigação sobre a experiência turística enquanto experiência mediada por diversos mecanismos semióticos, cognitivos e afetivos e comunicada por diversos meios, tanto de uma forma vertical quanto horizontal. Em foco estão a construção de representações dos lugares como destinos turísticos e as suas apropriações locais e individuais, bem como das figuras dos turistas, viajantes e das viagens, e questões como sejam a mercadorização das cidades (Pires, 2013), do consumo e das culturas (Silva et al., 2011), as dinâmicas do olhar turístico e das identidades, imaginários (Miranda, 2002; Gonçalves \& Rabot, 2010), a memória e a mediatização tecnológica (Carmelo, 2002).

A coletânea integra estudos de natureza empírica, relativos a casos circunscritos no espaço e tempo, onde se faz uso de dados reunidos a partir de diversas fontes (cartazes, vídeos, entrevistas, inquéritos), mas também reflexões teóricas de natureza fundamental e ensaios ilustrados com exemplos retirados da literatura de viagens. Partindo da filiação institucional dos seus autores, vemos que é diversa a sua proveniência disciplinar (Geografia, Antropologia, Sociologia, Estudos Culturais, Comunicação, Media, Turismo e Lazer, Estudos do Turismo) - e variada a sua origem geográfica (Espanha, Brasil e Portugal).

\section{DISCURSOS E IMAGENS NOS ESTUDOS DO TURISMO: DIMENSÕES DO DEBATE SOCIOANTROPOLÓGICO}

Para o antropólogo italiano Alessandro Simonicca $(2001,2007)$, nos estudos do turismo - e em particular na perspetiva socioantropológica -, podem-se distinguir dois modelos: o do tempo livre (leisure, loisir) ou político-económico e o semiológico. A primeira abordagem enfatiza o lazer e as suas pré-condições materiais como estatutos necessários para o turismo, considerando inclusive a necessária e incontornável assimetria que marca a atividade turística. E a segunda abordagem sublinha os significados simbólicos 
da atividade turística e seus desdobramentos, no âmbito da modelação do "olhar do turista" (tourist gaze).

A atividade turística na perspetiva político-económica é fundamentalmente uma circunstância derivada do tempo livre possibilitada por fatores sociais e económicos mais gerais. Deste ponto de vista, torna-se particularmente importante verificar os mecanismos de mediação entre as sociedades que geram e as sociedades que recebem turistas, no âmbito de uma divisão internacional do trabalho e das assimetrias políticas e económicas no plano global. Tais assimetrias resultariam da própria desigualdade estruturante que marca as relações entre visitantes e visitados, como uma metáfora do próprio contexto económico e político mais amplo (numa figuração tipo primeiro e terceiro mundos).

O trabalho de Nash (1996) é exemplar a esse respeito. Este autor vê o turismo como uma emulação do imperialismo, um signo de aculturação e um instrumento de poder político-ideológico num mundo organizado segundo um modelo centro-periferia, onde as zonas turísticas constituem locais de relaxamento e de descarga de tensões acumuladas nas metrópoles emissoras de turistas.

A abordagem político-económica destaca a formatação ideológica do destino turístico através de narrativas e imagens voltadas para a satisfação plena do turista. $A$ condição necessária desse processo passa pelo estabelecimento de uma relação transitória e desigual entre os que trabalham e os que fruem, reforçando assim um caráter de subserviência através da dominação e do controle do território do destino pelas elites locais a serviço do aparato turístico internacional (Crystal, 1992; Jurdao Arrones, 1992; Nash, 1989). Esses dispositivos de vigilância e domesticação não se encontrariam apenas na óbvia relação patrão-empregado-cliente/turista, mas antes na própria conceção do território como espaço turístico, ao reforçar padrões de dominação e de controle político (Chambers, 2000; De Kadt, 1991; Gascón \& Cañada, 2005). Desse modo, segundo alguns autores, haveria uma simbiose entre o turismo e os regimes políticos conservadores e totalitários, no sentido de que estes estariam interessados na manutenção e controle da ordem social e na projeção de uma imagem uniforme, tradicional e singularizada dos estados nacionais, elementos quase que condicionantes para o desenvolvimento da atividade turística e para a invenção de tradições (Anderson, 1983; Hobsbawm \& Granger, 1983)'

O modelo baseado na proeminência do olhar do turista ou modelo semiológico pressupõe, a partir do trabalho primordial de MacCannel (1976), que a atividade turística genuína seria fruto de uma transformação profunda da modernidade, quando se projeta a perspetiva visual como um dispositivo cognitivo e social privilegiado. Seria, pois, através do olhar que o sujeito moderno passaria a se relacionar com o mundo a partir de uma sensibilidade ocular, capturando-o como uma sobreposição de imagens

\footnotetext{
' O turismo e a imagem turística, inscritos na ditadura salazarista em Portugal, por exemplo, enfatizavam, dentro daquele projeto de nação, um mundo tradicional à guisa de um "paraíso perdido nas margens da Europa", projetado como um país "rural, pitoresco, tradicional, típico e quase pueril" (Pires, 2003, p. 36) e um "jardim da Europa" (Ziègler citado em Pires, 2003, p. 50).
} 
heteróclitas (Appadurai, 1995; Baudrillard, 1968/2007; Featherestone, 1995; Jameson, 2006; Lash \& Urry, 1994; Rushdie, 1991).

Dentro desse fluxo incessante de imagens, divisa-se a noção etérea e fugidia de paisagem como a projeção de um espaço exótico e exotizado segundo uma relação circular: o território significado enquanto paisagem seria um fragmento geomorfológico alheio ao mundo cotidiano de quem o projeta, idealiza e representa e que, por isso mesmo, passa a adquirir carateres singularizados e extraordinários. A perspetiva simmeliana é emblemática neste sentido. Para ele, a paisagem seria definida segundo uma espécie de fundamento total ou determinação (Bestimmtheit), um estado ou disposição (Gestimmtheit) para um ato do espírito pelo qual o sujeito modela um grupo de fenómenos para integrá-lo à categoria de paisagem. Simmel (1913/1996) compara uma paisagem a uma biblioteca: do mesmo modo que "um monte de livros não constitui uma biblioteca mas se torna uma, sem que se retire nem se acrescente um volume, a partir do instante em que um certo conceito unificador a envolve e lhe confere uma forma". A paisagem seria configurada, desse modo, pelo sentido que se atribui ao espaço físico imaginado. Assim, o sightseer-turista seria modelado segundo uma relação de alteridade gerada pelo olhar exótico (e panótico) que se projeta sobre o espaço.

O paradigma semiológico pode ser matizado a partir de duas tradições, ambas partindo do pressuposto de uma cisão de natureza simbólico-cognitiva própria ao ocidente industrial. Na perspetiva anglo-saxónica tem-se a proeminência do olhar turístico, isto é, uma orientação para uma análise sobre a formação das imagens do ponto de vista do turista (Chambers, 2000; MacCannel, 1976; Urry, 1990). A perspetiva, por assim dizer, "francesa" vai no sentido oposto: ressalta a configuração do imaginário da viagem e do turismo através da massificação mediática da vida social (Augé, 1998, 2001; Lagunas, 2007).

No centro do modelo semiológico está o vivo debate sobre a autenticidade. De acordo com Reisinger \& Steiner (2005), esse tema pode ser abordado a partir de três perspetivas: a primeira delas situa-o como uma problemática modernista, inaugurado pela querela entre Boorstin (1961) e MacCannel (1973, 1976), e marcada pela ideia de autenticidade significando o tradicional e o genuíno enquanto valores universais, numa visão romantizada e estática das sociedades não-industriais.

Enquanto que para Boorstin toda a experiência turística é superficial e inautêntica, marcada por pseudo-eventos, pelo fato de ser um reflexo do próprio mundo do consumo da sociedade de massas, para MacCannel (1976) o turista, tipo-ideal situado nas classes médias do ocidente industrial, buscaria na alteridade - da natureza, do passado ou do outro "étnico" - um mundo autêntico inexistente na sua vida cotidiana. E encontrá-lo-ia de forma comercializada e encenada no destino turístico (Greenwood, 1977), isto é, no cenário montado para a satisfação do turista (frontstage).

A segunda perspetiva pode ser classificada como construtivista e pressupõe que o autêntico resulta da realidade configurada a partir do olhar do observador e projetada através de estereótipos ocidentais sobre o outro. Assim, o autêntico se situaria não nos espaços em si, mas nas significações que lhes atribuímos, sendo o apelo mediático e publicitário um importante agente nesse processo. 
A terceira perspetiva inscreve-se dentro de uma matriz pós-moderna, para a qual a autenticidade não teria relevância para a fruição turística, sendo esta muito mais marcada pela rutura do quotidiano em busca de uma experiência hedonística intensa do que por uma busca por uma experiência existencial profunda, no sentido de uma excitação no lazer através de um descontrole controlado, aproximando-se das proposições de Elias e Dunning (1992). Esse ponto marca uma crítica a MacCannel. Tanto pelo fato de que não só não se pode inferir empiricamente sobre a condição do turista como um "nómada espiritual" ou um "estruturalista arquetípico em busca do outro e do eu autênticos" (MacCannel, 1976; Selwyn, 1996), como também porque a busca pela autenticidade não é condição necessária para a prática do turismo².

Assim, os turistas podem muito bem ir a tal ou tal destino motivados por uma fruição segundo o modelo " 5 " (sun, sea, sand, saving and sex), estabelecendo um contato mínimo com a população local, já que protegidos por uma "bolha ambiental" (enviromental bubble) promovida pelos intermediários institucionais do turismo. Aliás, este é o modelo mais recorrente, segundo a literatura especializada (Cohen, 1988; Crick, 1992). Além disto, muitas vezes o próprio turista está consciente das encenações de autenticidade promovidas localmente, e desse modo parece estar muito mais predisposto, como indicam Graburn \& Barthiel-Bouchier (2001) e Jafari (2007), ao gozo da estadia turística dentro de um marco ritualizado do que à sua fruição como uma atualização mítica. Embora ambas as perspetivas não sejam necessariamente auto-excludentes.

Franklin e Crang no editorial de lançamento em 2001 da revista Tourism Studies chamam a atenção para o desenvolvimento de novas formas de abordar o turismo pelo viés da semiótica, enformadas pela metáfora da performance introduzida por MacCannel nos Estudos do Turismo. Aí a visão é considerada como apenas um dos sentidos envolvidos na experiência turística, e não como tendo um papel determinante na construção de um sentido para a mesma. Estas investigações, que abordam o turismo como um sistema produtivo que funde "discurso, materialidade e prática" (2001, p. 17), dão conta das mudanças verificadas nas culturas turísticas atuais cada vez mais centradas na incorporação das experiências (Edensor, 2009).

Como vimos, a questão da significação e, portanto, dos mecanismos semióticos presentes no turismo enquanto prática sociocultural e económica, constitui-se desde há muito como preocupação central no estudo do turismo. O entendimento mais comum tem sido o do discurso não como uso de signos, verbais, visuais, ou outros, mas sim como veículo que estrutura e é estruturado por processos sociais e políticos, regimes de verdade/visualidade e imaginários coletivos. O mesmo se passa relativamente às imagens, entendidas essencialmente como representações que mediam, enformam e resultam da experiência turística e como espaços de articulação de discursos mais ou menos reguladores. Permanecem, assim, ainda pouco explorados os usos que, no quadro da paisagem

\footnotetext{
${ }^{2}$ Corrobora neste sentido a figura do pós-turista, que seria exatamente o sujeito que busca o gozo de experiências baseadas em encenações claramente inautênticas (Rojek \& Urry, 1997; Urry, 1994) num marco do kitsch, do pastiche ou da pura replicação de cenários que se remetem a "originais" que já seriam em si mesmos simulacros, como os cowboys tailandeses descritos por Cohen (2005).
} 
linguística (fluxo de signos linguísticos - tourist linguascape, Jaworski \& Thurlow, 2010) de um turismo global, os sujeitos turistas (McCabe, 2005) e o sistema turístico fazem, em ambientes culturais e interacionais específicos, dos recursos linguísticos, visuais e outros para construir a experiência turística e para a comunicar através dos mais diversos meios. O aprofundamento do estudo dessas práticas permitiria não só evidenciar aspetos comuns do que significa ser turista e agir como tal, como também variações, dinâmicas e diferenças locais e individuais. Por esta via, ao invés de darmos como certos ou fixos os significados das categorizações que têm estruturado a problematização do turismo, estaríamos a dar a importância devida aos aspetos fluídos e contingentes da produção dos significados. Ou seja, estaríamos mais próximos da realidade turística.

\section{INTRODUZINDO A COLETÂNEA}

O primeiro segmento deste volume inclui textos centrados nos processos de construção da imagem dos lugares como destinos turísticos e nos processos de perceção da mesma. A imagem é aqui entendida como representação sígnica de natureza material e como representação cognitiva e afetiva. Interrogam-se os discursos expressos e (re) produzidos nas imagens dos destinos turísticos e os seus significados socioculturais.

No primeiro artigo, Luis Alfonso Escudero Gómez traz para a discussão o bem reconhecido problema, no quadro dos estudos do turismo cultural, da espectacularização das urbes associada a estratégias institucionais de marketing para promover as cidades como destinos turísticos. Nesses esforços de criação de valor de marca, mobilizam-se de forma seletiva elementos das culturas, do património e da história na construção das cidades como destinos turísticos e na procura de imagens que as identifiquem, distingam, posicionem e garantam um lugar seguro na memória sensorial, afetiva e corporal dos sujeitos turistas consumidores. Partindo do conceito de imagem como representação mental, o autor propõe-se estudar o impato da imagem na motivação e tomada de decisão do turista, partindo de um estudo de caso. Toledo, um dos principais destinos da Península ibérica, é o exemplo escolhido. A questão principal do artigo consiste em averiguar se a imagem promocional e mediática de Toledo determina a decisão de escoIha de destino dos visitantes. Com base numa análise dos conteúdos da imagem promocional de Toledo e dos resultados de uma investigação empírica da perceção dos seus visitantes, conclui-se que há uma convergência entre a imagem cultural construída e a imagem percebida. Isto é, o visitante procura, espera encontrar, encontra, recebe e recomenda Toledo a outros precisamente com base em traços estereotipados fundamentais da imagem de Toledo como destino cultural.

Num tom crítico, sublinha-se que essa imagem, baseada uma visão fragmentada da história e no caráter pitoresco do património, faz "desaparecer a realidade social" da cidade. $\mathrm{O}$ artigo encerra com um alerta aos produtores de marcas e imagens de destinos turísticos para a necessidade de contrabalançar objetivos de comercialização e mercadorização das cidades com preocupações de "preservação da essência urbana" de forma a evitar riscos associados à monocultura do turismo. 
O segundo caso em destaque é o da imagem promocional do Rio de Janeiro. Maria Alice de Faria Nogueira e Luiz Flavio La Luna Di Cola questionam o papel das imagens mediáticas no processo de construção de um "olhar do turista" que regula as performances e mesmo a compreensão de formas de agir dos sujeitos turistas, mas também dos locais, em espaços urbanos comercializados como destinos turísticos.

A discussão assenta numa análise comparativa entre os conteúdos de cartazes de viagens de companhias áreas, criados entre as décadas de 1910 e 1970, e os das imagens televisivas da Cerimônia de Abertura dos Jogos Olímpicos Rio 2016. Trata-se de uma análise onde o contexto sociohistórico de produção assume especial relevância. Os investigadores defendem que o olhar do turista que durante décadas enformou a imagem do Rio de Janeiro como destino turístico, associando-o à ideia de paraíso, seja, de "Cidade Maravilhosa", foi um "olhar estrangeiro", partilhado em grande medida pelos próprios habitantes da cidade. Em comparação com esse olhar, as imagens da cerimónia de abertura dos Jogos Olímpicos Rio 2016, que projetam a imagem do Rio como "Cidade Olímpica", consubstanciam um novo olhar do turista que integra a perspetiva dos habitantes, pondo em destaque uma visão de um Rio mais urbano e performático, no qual o viajante vive a experiência da cultura e do lugar como um habitante da cidade.

$\mathrm{O}$ caso que encerra esta parte do volume dedicada às imagens do turismo cultural é-nos trazido por Patrícia Lima, dos Estudos Culturais. Neste artigo, o turismo é abordado como uma atividade de consumo e um fenómeno da cultura de massa contemporânea, parte dos fenómenos de mobilidade que marcam a experiência da globalização. Propõe-se uma leitura interpretativa de um filme publicitário, promovido pelo Turismo de Portugal, que integrou uma campanha online, lançada em 2017, voltada para os públicos internacionais. Que representação está em causa nesta construção de Portugal como destino turístico, é a questão diretora do exercício proposto. Mobiliza-se para a discussão o conceito de consumo da experiência, onde o que está em jogo não é a prática do consumo, mas sim a experiência do mesmo, sendo, portanto, a experiência o próprio objeto a ser consumido.

Argumenta-se que no discurso promocional promovido pela campanha em causa os valores da experiência e das emoções, associados à ideia de viagem, têm um papel central. É através deste viés que são definidas as atrações já difundidas anteriormente de Portugal como destino turístico. Patrícia Lima defende que a aposta neste tipo de estratégia, que vemos repetida noutras campanhas turísticas contemporâneas, vive das possibilidades oferecidas pelos ecrãs, interrogando também a tendência de individualização e personalização caraterística dos esforços promocionais do turismo na atualidade.

No artigo de Agustín Santana-Talavera o interesse pelas imagens dos destinos turísticos concretiza-se numa proposta de um modelo de compreensão dos processos de criação e de controlo desse tipo de imagens. Consciente da impossibilidade de distinguir o poder das imagens construídas pelo sistema turístico do poder das imagens divulgadas pelos média sem intenção de promoção turística, o autor considera ainda assim inegável a sua importância na cultura ocidental ao fazer de cada sujeito um passageiro desejoso de experienciar o seu "paraíso particular". 
Para compreender esse poder de forma global, é necessário, diz-nos o autor, partir de um enfoque sistémico processual em que se distingam claramente os processos de construção da imagem vendida, de natureza institucional e coletiva, dos processos de perceção e interiorização, de natureza individual. Em torno das várias dimensões que atribui à imagem (autoimagem, a imagem projetada, a imagem percebida e a imagem compartilhada), Santana-Talavera aponta, de forma crítica, o que se tem feito e o que importa fazer em termos de investigação e discussão neste domínio. Sublinha que a incorporação da autoimagem, isto é, aquela percebida pelos residentes de si mesmos, não sendo única, pode agregar veracidade às campanhas publicitárias e que o entendimento dos processos de perceção da imagem deve ser complexificado, uma vez que são muitos os fatores que os podem afetar.

O segundo conjunto de artigos versa sobre os discursos do turismo cultural que constroem a herança patrimonial dos lugares reinventando por essa via identidades locais e nacionais. A memória e sua recuperação ocupam um lugar central nas sociedades contemporâneas e o discurso do turismo cultural concorre para essa importância. Como refere Richards (2018, p. 6), um dos fundamentos principais do turismo cultural têm sido os recursos materiais e simbólicos que compõem a herança patrimonial dos lugares que se contemplam e visitam. $\mathrm{O}$ artigo de Ana Isabel Inácio centra-se no caso dos museus vínicos com o intuito de compreender como reconstroem a herança enológica dos territórios e o papel que têm no fenómeno do enoturismo. Nele expõem-se os resultados de um estudo relativo à mais antiga região vitivinícola demarcada do país, fundada em 1756 e situada na região do Douro, onde se procurou destacar a forma como a identidade e a herança enológica são promovidas e comunicadas neste tipo de espaços.

A autora sublinha que os museus do vinho são "guardiões" de memória e de discursos sobre o passado e o presente vitivinícola das regiões que representam, mas também espaços de seleção e exclusão que permitem muitas vezes a (re)construção do passado. Através de uma análise de conteúdo das exposições existentes nos vários espaços selecionados, argumenta-se que o discurso destes museus, ao incidir sobre o processo produtivo e as dinâmicas económicas criadas, deixando de lado questões sociais, como as de género ou hierarquia social, promove uma identidade que é em certa medida "pacífica".

Belmira Coutinho et al. trazem-nos outro caso, concernente ainda ao território português, da forma como a história tem sido transformada e transmitida como herança. Em causa estão os usos do património herdado da ditadura em Portugal. A proposta do artigo reside em olhar para este tipo de património à luz do conceito de património dissonante e interrogar as relações que o mesmo entretêm com o chamado turismo de morte e de sofrimento. Da análise realizada conclui-se que o uso turístico do património do Estado Novo é feito com a perda ou até o apagamento das caraterísticas que ligam esses espaços ao seu passado durante a ditadura. Os autores perguntam-se se espaços que foram convertidos em hotéis não poderiam integrar informação turística relativa ao seu passado dissonante.

O terceiro bloco de artigos incide sobre os viajantes, subjetividades e práticas relacionadas e processos da sua construção discursiva. Partindo da ideia que o facto turístico 
é um facto social total, Christine Escallier reflete em torno das motivações do viajante, propondo-se evidenciar, através de citações literárias, como se viajou ao longo do tempo, a evolução do perfil do viajante e aquilo em que se tornou no início do século XXI.

Segundo a autora, com a viragem do século, entreveem-se duas tendências significativas: um turismo influenciado pela moda étnica e um turismo solidário. No exercício da análise diacrónica realizada, interroga-se a validade da distinção clássica entre viajante e turista, profissional e amador da viagem, com o argumento que a viagem se basta a si própria: a experiência da viagem, diz-se, tem em si própria virtudes, ligadas ao conhecimento do eu e do outro e de outros lugares. Importaria, portanto, conclui a investigadora, que a Antropologia chamasse a si a educação turística no sentido de fomentar uma reflexão compartilhada entre turistas e nativos sobre a descoberta de outras culturas.

Continuando a reflexão em torno do ato de viajar como uma experiência significativa para o enriquecimento humano, Camila Aparecida Leves Maneze e Reinaldo Tadeu Boscolo Pacheco analisam o desenvolvimento da figura do viajante independente, a partir de relatos de viagens ficcionais e reais, com o objetivo de destacar como as experiências de viagens podem resultar numa descoberta do eu e do outro. Situam o surgimento da figura do viajante independente no cenário do mundo contemporâneo onde as viagens deixaram de ser apenas símbolos de estatuto e passaram a integrar a busca quotidiana mais generalizada por experiências e sensações.

Contrapondo a figura do viajante independente quer à figura do turista quer à do viajante épico, destaca-se que esta forma de viajar, cujo traço central é a autonomia, permite recuperar o sentido da viagem e afirma-se como um momento simultaneamente sagrado e profano, em consequência da liberdade, aventura e errância que caraterizam essa forma de viajar.

Considerando que a coleção de lugares das viagens pode não ser a principal motivação das viagens, mas que ainda assim constitui, juntamente com a ato de contabilização das mesmas, uma prática social, que confere prestígio e legitimidade a quem coleciona, João Sarmento e Patrícia Lopes centram-se nesta prática para a tentar delimitar e propor uma forma de a contabilizar que integra variáveis usualmente descartadas nas metodologias de contabilidade propostas por diversos organismos.

Entrevistas a viajantes com grande experiência, selecionados por conveniência, constituem a base a partir da qual se discute e ajusta o modelo proposto, que integra também uma proposta para uma partição de territórios à escala global. Os autores salientam que visam promover a discussão em torno das práticas de contabilização das viagens e da divisão territorial do mundo, a partir de uma abordagem das viagens como coleções.

O terceiro tema abordado neste volume refere-se à relação entre o turismo do património cultural e as tecnologias digitais. Pedro Andrade apresenta um resumo de um estudo empírico sobre a mobilidade dos visitantes de museus. Esse estudo foi desenvolvido num quadro de um projeto sobre a comunicação pública da arte e envolveu a aplicação de um questionário a visitantes de um museu no quadro de uma exposição de arte, de entre os quais se destaca o sujeito turista. Situando a sua proposta no quadro 
da problemática das mobilidades urbanas e do turismo cultural, o investigador dá conta de três das múltiplas dimensões do turismo cultural móvel (espaço, tempo e discursos) e propõe uma metodologia fundamentada nas mesmas.

Fernando Augusto Silva Lopes aborda as visitas virtuais aos museus enquanto possibilidade turística mediada de acesso à cultura. A ferramenta digital em destaque é o Google Arts and Culture, abordada como um instrumento que cria uma nova forma cognitiva de produzir e consumir bens simbólicos e como uma forma de mediação. O autor discute o deslocamento do lugar da cultura que daí deriva. Com base nos resultados de um estudo empírico que envolveu a formação de grupos de foco, sustenta que o acesso virtual aos museus parece constituir-se como uma forma válida de acesso às artes e uma experiência cultural representativa, criando, portanto, uma possibilidade turística real, digna de ser explorada com mais atenção.

Encerramos o volume com um texto de António Sérgio Araújo de Almeida onde se enquadra o turismo como atividade global de integração internacional, por via do conhecimento e respeito mútuo dos povos e como atividade local de integração. Partindo do lugar central que o valor da experiência adquiriu no turismo, o autor argumenta a favor da intensificação da mesma por via da exploração estratégica de traços identitários, uma aposta que, diz-se, poderá contribuir para a sustentabilidade dos territórios e para a emancipação das comunidades locais.

A secção "Varia" integra um texto que explora a relação entre património arquitetónico, memória e preservação ambiental. Hermes de Andrade Júnior et al. trazem-nos o caso das fortificações da Baía da Guanabara sitas no Rio de Janeiro e a experiência de educação ambiental desenvolvida com alunos militares. Com recurso a entrevistas semiestruturadas, evidenciam atitudes ambientais de agentes de preservação da área de proteção ambiental do Leme e os resultados do uso que delas fizeram num exercício de sensibilização ambiental.

No quadro da edição deste volume, quisemos auscultar a opinião de investigadores das Ciências Sociais sobre o estado da arte na área do turismo cultural no Brasil e em Portugal. Susana de Araújo Gastal, professora titular e pesquisadora do Programa de Pós-Graduação em Turismo e Hospitalidade da Universidade de Caxias do Sul (Brasil), autora de diversos livros e artigos relativos à temática de cultura e turismo, e Carlos Alberto Steil, Professor Permanente do Programa de Pós-Graduação em Antropologia Social e do Programa de Pós-Graduação em Políticas Públicas da Universidade Federal do Rio Grande do Sul (Brasil), autor de diversas obras referentes à temática antropológica, religião, política e deslocamentos humanos, foram os investigadores que gentilmente acederam ao nosso convite, respondendo por escrito às questões formuladas. São estes dois contributos que integram a secção da revista dedicada às entrevistas.

O volume encerra com "Leituras", onde incluímos a revisão crítica que Daniel López Zamora faz de obra Instagram and contemporary image publicada em 2017 por Lev Manovich, professor de Ciências de Computação na City University de Nova Yorque e teórico de referência mundial no campo da cultura digital e artes, que deixa evidente a pertinência de investigar, nos estudos do turismo cultural, os usos desta plataforma. 


\section{REFERÊNCIAS}

Appadurai, A. (1995). The production of locality. In R. Fardon (Ed.), Counterworks: managing the diversity of knowledge (pp. 178-199). Londres e Nova lorque: Routledge.

Anderson, B. (1983). Imagined communities. Londres: Verso.

Andrade, P. (2017). Cultural e-tourism depicted by digital discourse: innovative mobilities at urban e-heritage networks. In M. Bielenia-Grajewska \& M. Ríos (Eds.), Innovative perspectives on tourism discourse (pp. 1-17). Hershey: IGI Global.

Araújo, E., Cogo, D. \& Pinto, M. (2015). Mobilidades, media (ções) e cultura. Comunicação e Sociedade, 28, 7-14. DOI: $10.17231 /$ comsoc.28(2015).2267

Augé, M. (1998). El viaje imposible: el turismo y sus imágenes. Barcelona: Gedisa.

Augé, M. (2001). Rapports entre tourisme, culture et territoire. In Turisme i Cultura. Debats del Congrés de Turisme Cultural (pp. 21-31). Saló Internacional del Turismo a Catalunya. Barcelona: Fundació Interarts.

Baudrilard, J. (1968/2007). A sociedade de consumo. Lisboa: Edições 70.

Brambília, A. \& Baptista, M. M. (2016). Os estudos culturais aplicados ao turismo. In F. Filho \& M. M. Baptista (Eds.), Estudos Culturais e interfaces. Objetos, metodologias e desenhos de investigação (pp. 104122). Aveiro: Universidade de Aveiro, Programa Doutoral em Estudos Culturais. Santa Maria: UFSM, Programa de Pós-Graduação em Comunicação.

Boorstin, D. (1961). The image: a guide to pseudo-events in America. Nova lorque: Harper \& Row.

Cadavez, M. C. (2013). Cultural lessons: the case of Portuguese tourism during Estado Novo. In M. Smith \& G. Richards (Eds.), The Routledge handbook of cultural tourism (pp. 89-93). Nova lorque: Routledge.

Chambers, E. (2000). Native tours: the anthropology of travel and tourism. Long Grove: Waveland Press.

Carmelo, L. (2002). Imaginação e imaginário. Um jogo actual entre a vertigem, anuetralização e as idealidades. Comunicação e Sociedade, 4, 131-145. DOI: 10.17231/comsoc.4(2002).1287

Cohen, E. (1988). Authenticity and commoditisation in tourism. Annals of Tourism Research, 15(3), 371-386.

Cohen, E. (2005). Principales tendencias en el turismo contemporáneo. Política y Sociedad, 42(1), 11-24.

Crick, M. (1992). Representaciones del turismo internacional en las ciencias sociales: sol, sexo, paisajes, ahorros y servilismos. In F. J. Arrones (Ed.), Los mitos del turismo (pp. 339-404). Madrid: Endimión.

Cunha, M. P. da (2015). As duas faces da cultura: usos e sentidos de uma noção. In J. Durand \& H. Martins (Eds.), Olhares e oficios de antropólogos em Espanha e Portugal (pp. 269-291). Picote: Ed. Frauga.

Culler, J. (1989). The semiotics of tourism. In J. Culler, Framing the sign: criticism and its institutions (pp. 153167). Norman: University of Oklahoma Press.

Crystal, E. (1992). El turismo en Toraya (Sulawesi, Indonesia). In V. Smith (Ed.), Anfitriones e invitados: Ia antropología del turismo (pp. 217-256). Madrid: Endymion.

Dann, G. M. S. \& Parrinello, G. L. (Eds.) (2009). The sociology of tourism: European origins and developments. Bingley, RU: Emerald, Tourism Social Science Series.

De Kadt, E. (Ed.) (2001). Turismo: pasaporte al dessarolo? Madrid: Endymion. 
Edensor, T. (2009). Tourism and performance. In T. Jamal \& M. Robinson, M. (Eds.), The Sage handbook of Tourism Studies (pp. 543-557). Londres: Sage.

Elias, N. \& Dunning, E. (1992). A busca da excitação. Lisboa: Difel.

ET27 (2016). Estratégia Turismo 2027 Portugal. Turismo de Portugal, I.P. Governo de Portugal.

Francesani, S. (2014). Reading tourism texts. Bristol: Channel View Publications.

Franklin, A. \& Crang, M. (2001). The trouble with tourism and travel theory? Tourist Studies, 1(1) 5-22.

Featherstone, M. (1995). Cultura de consumo e pós-modernismo. São Paulo: Studio Nobel.

Fernandes, J. L. (2016). Redes, paisagens culturais e diásporas: entre a atração turística e a afirmação identitária e política. In F. V. Castro, J. L. Fernandes \& R. Gama (Eds.), Redes, capital humano e geografias da competitividade (pp. 12-38). Coimbra: Imprensa da Universidade de Coimbra. Retirado de https:// digitalis-dsp.uc.pt/bitstream/10316.2/39065/1/Redes\%2opaisagens\%2oculturais\%20e\%2odiasporas. pdf

Fortuna, C. (2008). Cidadãos, turistas e flâneurs: Reflexões sobre o turismo, o turista e a cidade. In Associação Portuguesa de Sociologia (Eds.), Práticas e processos da mudança social (pp. 1-7), Coimbra: Celta Editora.

Gascón, J. \& Cañada, E. (2005). Viajar a todo tren. Turismo, desarrollo y sostenibilidad. Barcelona: Icaria.

Graburn, N. \& Barthiel-Boucher, D. (2001). Relocating the tourist. International Sociology, 16(2), 147-158.

Joaquim, G. (2015). Viajantes, viagens e turismo. Lisboa: Editora Mundos Sociais.

Gonçalves, A. \& Rabot, J. (2010). Nota introdutória. A modernidade e pós-modernidade em foco. Comunicação e Sociedade, 18, 7-9. DOI: 10.17231/comsoc.18(2010).1003

Grennwood, D. (1977). Culture by the pound. An anthropological perspective on tourism as a cultural commoditization. In V. Smith (Ed.), Hosts and guests: the anthropology of tourism (pp. 129-138). Philadelphia: University of Pennsylvania Press.

Heller, M., Jaworski, A. \& Thurlow, C. (2014). Introduction: sociolinguistics and tourism. Mobilities, markets and multilingualism. Journal of Sociolinguistics, 18(4), 425-445.

Hobsbawm, E. \& Granger, T. (Ed.) (1983). The invention of tradition. Cambridge: Cambridge University Press.

Jafari, J. (2007). Modelos del turismo: los aspectos socioculturais. In D. Lagunas (Ed.), Antropología Y turismo. Claves culturales y disciplinares (pp. 47-71). México, D. C.: Plaza y Valdés.

Jameson, F. (2006). A virada cultural: reflexões sobre o pós-moderno. Rio de Janeiro: Civilização Brasileira.

Jamal, T. \& Robinson, M. (Ed.) (2009). The Sage handbook of Tourism Studies. Londres: Sage.

Jaworski, A. \& Pritchard, A. (2005). Discourse, communication and tourism. Clevedon: Channel View.

Jaworski, A. \& Thurlow, C. (2010). Language and the globalizing habitus of tourism: towards a sociolinguistics of fleeting relationships. In N. Coupland (Ed.), The handbook of language and globalization (pp. 225-286). Oxford: Wiley-Blackwell.

Jurdao Arrones, F. (1992). Los mitos del turismo. Madrid: Endymion.

La Rocca, F. (2017). A mutação visual do mundo social. Revista Lusófona de Estudos Culturais, 3(2), 25-35. 
Lagunas, D. (Ed.) (2007). Antropología y turismo. Claves culturales y disciplinares. México, D. C.: Plaza y Valdés.

Lash, S. \& Urry, J. (1994). Economies of signs and space. Londres: Sage.

McCabe, S. (2005). 'Who is a tourist?' A critical review. Tourist studies, 5(1) 85-106.

MacCannell, D. (1976). The tourist: A new theory of the leisure class. Nova lorque: Schocken Books.

MacCannell, D. (1973). Staged authenticity: arrangement of social space in tourist setting. American Journal of Sociology, 79, 586-603.

Martins, M. L. (2002). O trágico como imaginário da era mediática. Comunicação e Sociedade, 4, 73-79. DOI: $10.17231 /$ comsoc.4(2002).1265

Martins, M. L. (2007). Nota introdutória. A época e as suas ideias. Comunicação e Sociedade, 12, 5-7. DOI: $10.17231 /$ comsoc.12(2007).1092

Martins, M. L. (2015). Os estudos culturais como novas humanidades. Revista Lusófona de Estudos Culturais, $3(1), 341-361$.

Marujo, N. (2014). A cultura, o turismo e o turista: que relação? Revista Turydes, 7(16), 1-12.

Miranda, J. (2002). Controlo e descontrolo do imaginário. Comunicação e Sociedade, 4, 49-72. DOI: 10.17231/ comsoc.4(2002).1264

Moore, K. (2002). The discursive tourist. In G. Dann (Ed.), The tourist as a metaphor of the social world (pp. 41-59). Wallingford, Oxon: Cabi Publishing.

Nash, D. (1996). Anthropology of tourism. Nova lorque: Pergamon.

Nash, D. (1989). El turismo considerado como una forma de Imperialismo. In V. Smith (Ed.), Anfitriones $e$ invitados: la antropología del turismo (pp. 217-256). Madrid: Endymion.

Noval, V. \& Serra, P. (Eds.) (2018). Cultura, património e turismo na sociedade digital. Uma perspetiva Ibérica. Covilhã: LabCom Books.

Pereiro, X. (2009). Turismo cultural. Uma visão antropológica. El Sauzal: Pasos.

Pereiro, X. \& Fernandes, F. (2018). Antropologia e turismo. Teorias, métodos e praxis. El Sauzal: Pasos.

Pires, H. (2013). Usos do espaço, liberdades e constrangimentos. São Paulo, cidade limpa: estudo de caso. Revista Lusófona de Estudos Culturais/Lusophone Journal of Cultural Studies, 2(1), 234-248. Retirado de http://rlec.pt/index.php/rlec/article/view/35

Pires, E. (2003). O baile do turismo: turismo e propaganda no Estado Novo. Casal de Cambra: Caleidoscópio.

Reisinger, Y. \& Steiner, C. (2005). Reconceptualizing object authenticity. Annals of Tourism Research, 33(1), $65-86$.

Richards, G. (2018). Cultural tourism: a review of recent research and trends. Journal of Hospitality and Tourism Management, 36, 12-21.

Richards, G. (2007). Cultural tourism: global and local perspectives. Nova lorque: Haworth Press.

Rojek, C. \& Urry, J. (Eds.) (1997). Touring cultures: transformations of travel and theory. Londres: Routledge

Rushdie, S. (1991). Imaginary homelands. Londres: Granta. 
Sampaio, S. (2013). Portuguese cultural studies/cultural studies in Portugal: some thoughts on the making and remaking of a field. Culture Unbound: Journal of Current Cultural Research, 5, 73-88.

Sampaio, S. (2017). Tourism, gender and consumer culture in late and post-authoritarian Portugal. Tourist Studies, 17(2), 200-217.

Selwyn, T. (1996) (Ed.). The tourist image: myths and myth making in tourism. Chichester: John Wiley \& Sons.

Silva, M. C. da (2010). Mauritanian guestbook. Shaping culture while displaying it. In P. Burns, C. Palmer \& J. A. Lester (Eds.), Tourism and visual culture. Theory and concepts (pp. 181-191). Oxfordshire: CABI.

Silva, S., Galhardo, A. \& Torres, R. (2011). O ritual da comunicação e o ritual do consumo: novas tribos, novos rituais. Comunicação e Sociedade, 19, 301-315. DOI: 10.17231/comsoc.19(2011).913

Smith, M. (2009). Issues in cultural tourism studies. Londres: Routledge.

Smith, E. \& Mike Robinson (Eds.) (2005). Cultural tourism in a changing world. Politics, participation and (re) presentation. Clevedon: Channel View Publications.

Simonicca, A. (2001). Antropologia del turismo: strategie di ricerca e contesti etnografici. Roma: Carocci.

Simonicca, A. (2007). Conflicto(s) e interpretación: problemas de la antropología del turismo en las sociedades complexas. In D. Lagunas (Ed.), Antropología y turismo. Claves culturales y disciplinares (pp. 27-46). México, D. C.: Plaza y Valdés.

Simmel, G. (1913/1996). A filosofia da paisagem. Política e Trabalho, 12, 15-24.

UNWTO (2018). Report on tourism and culture synergies. Madrid: UNWTO.

Urry, J. (1990) The tourist gaze: leisure and travel in contemporary Societies. Londres: Sage.

Urry, J. (1994). Cultural change and contemporary tourism. Leisure Studies 13, 233-238.

Urry, J. (2007). Mobile cultures. Retirado de http://www.comp.lancs.ac.uk/sociology/papers/Urry-MobileCultures.pdf

Yúdice, G. (2007). Economia da cultura no marco da proteção e promoção da diversidade cultural. University of Miami. Retirado de https://works.bepress.com/george_yudice/4/

\section{NOTAS BIOGRÁFICAS}

Zara Pinto-Coelho, Doutorada em Ciências da Comunicação - Semiótica Social, pela Universidade do Minho, é Professora Associada do Departamento de Ciências da Comunicação da Universidade do Minho onde leciona sociologia da comunicação, estudos do discurso e semiótica social. A sua pesquisa está centrada nas teorias do discurso e nas suas aplicações críticas aos estudos mediáticos e culturais em tópicos como saúde pública, género, heterossexualidade, participação pública. É coordenadora da linha de investigação em Estudos Culturais do Centro de Investigação em Comunicação e Sociedade da Universidade do Minho, Portugal, e um dos editores da Revista Lusófona de Estudos Culturais.

Email: zara@ics.uminho.pt 
Morada: Departamento de Ciências da Comunicação, Instituto de Ciências Sociais, Campus de Edifício 15, 4710-057, Gualtar, Braga, Portugal

Roque Pinto é antropólogo, Doctor Europaeus em antropologia cultural pela Universidad de La Laguna (Espanha), Professor Titular de antropologia na Universidade Estadual de Santa Cruz (Brasil), atualmente desenvolve trabalhos em cooperação com investigadores brasileiros e estrangeiros em tópicos relacionados às temáticas de Desenvolvimento Local; Território e Poder; Turismo; Consumo; Saúde Pública; Segurança Pública.

Email: roquepintosantos@gmail.com

Morada: Universidade Estadual de Santa Cruz, Departamento de Filosofia e Ciências Humanas, Campus Soane Nazaré de Andrade, Rodovia Jorge Amado, Km 16, Bairro Salobrinho, CEP 45662-900. Ilhéus-Bahia-Brasil 